\title{
Energy drink and risk of arrhythmias: Recommendations for a safer use in young adolescents
}

\author{
Santomauro $M^{1 *}$, Riganti $C^{2}$, Giordano $R^{1}$, Petretta $M^{3}$, Santomauro $M A^{1}$, Bonaduce $D^{3}$ and Levy $S^{4}$ \\ ${ }^{1}$ Department of Cardiovascular Emergency, Internal medicine and Geriatric, Federico II University of Naples, Italy \\ ${ }^{2}$ Direction of Public Health, Federico II University of Naples, Italy \\ ${ }^{3}$ Department of Translational Medicine, Federico II University of Naples, Italy \\ ${ }^{4}$ School of Medicine, University of Méditerranée, Marseille, Division of Cardiology, Hôpital Nord, Marseille, France
}

\section{Introduction}

Large epidemiologic studies have failed to find a connection between the amount of caffeine use and the development of arrhythmias. As such, it does not make sense to suggest that patients with palpitations, paroxysmal atrial fibrillation, or supraventricular tachycardia is produced from caffeine use. The main toxicity caused by caffeine is due to the increase in intracellular calcium concentration, which leads to a catecholamine surge that sensitizes dopamine receptors resulting in supraventricular or ventricular arrhythmias and death ultimately at very high doses [1-7]. Energy drinks (EDs) are a new corner on the beverage market, with $30-50 \%$ of young adults and teens using them regularly. EFSA (European Food Safety Authority) has published a report on a commissioned study that for the first time collates data on the consumption of EDs at European level for specific population groups, including children and adolescents. The study also estimates consumers [8] exposure, through both acute and chronic consumption, to some active ingredients found in EDs primarily caffeine, taurine and D-glucurono-lactone. The study found that, among respondents, the age group most likely to consume EDs was adolescents (68\% of total respondents) and that EDs when consumed by children aged 3 to 10 years account for an estimated $43 \%$ of their total caffeine exposure. The key findings from the study are as follows: Adolescents (10-18 years): approximately $68 \%$ of those interviewed were consumers of EDs. Among these, about 12\% were "high chronic" consumers, with an average consumption of 7 litres a month, and 12\% were "high acute" consumers. Children (3-10 years): approximately $18 \%$ of those interviewed were consumers of EDs. Among these, around 16\% were "high chronic" consumers, with average consumption of 0.95 litres a week (almost 4 litres per month). In our recent experience in young student of Naples the majority of users consumed one ED to treat most situations, although using three or more was a common practice to drink with alcohol while partying (53\%) and before or during sport practice (68\%) [9].

EDs are loaded with caffeine, sugar, and other chemicals that can stimulate the cardiac system. There is an increasing body of mainly anecdotal case reports describing arrhythmias or even sudden death triggered by exercise plus using EDs. EDs contain a variety of substances, but caffeine is the main component. Safety has been the biggest concern associated with consuming EDs. Recently, ED-associated emergency visits have sharply increased [3]. They are often found in combination with other substances, such as alcohol and drugs of abuse, which further potentiates the effect of EDs [4]. EDs have been recognized to cause cardiovascular changes, particularly cardiac arrhythmias (Supraventricular arrhythmia, Ventricular arrhythmia) and elevated blood pressure, increased heart rate, increased QTc interval, Coronary artery spasm, Coronary artery thrombosis, Takotsubo cardiomyopathy, ST-Segment Elevation Myocardial Infarction (STEMI), Sudden cardiac death, Endothelial dysfunction [1]. It is unknown what makes some people more susceptible to arrhythmias. It may be that some individuals are genetically susceptible to the effects of EDs, resulting in arrhythmias or it may be the actual acute ingestion of EDs putting the patient at risk of arrhythmias [10-20].

\section{Regulation of energy drinks}

The FDA imposes a limit of $71 \mathrm{mg}$ of caffeine per $12 \mathrm{fl} \mathrm{oz}$ of soda. EDs manufacturers may circumvent this limit by claiming that their drinks are "natural dietary supplements". Thus, safety determinations of energy drinks are made solely by the manufacturers, and there are no requirements for testing, warning labels, or restriction against sales or consumption by minors. In contrast, over-the-counter dedicated caffeine stimulants must list the minimum age for purchase (14 years), adverse effects, cautionary notes, recommended dose, and the total daily recommended dose of caffeine. In November 2009, the FDA asked manufacturers of non-alcoholic EDs to prove their safety [7]. The US Senate is considering a bill that would require supplement manufacturers to register annually with the FDA and allow FDA recalls of supplements suspected of being unsafe. Ingredients may also be restricted to those that have already been approved by the FDA. Regulatory controversies also extend internationally. When France banned Red Bull, the manufacturers challenged the ban through the European Commission, which determined that the caffeine and taurine concentrations in EDs had not been proven to health risks and ordered France to lift the ban; the European Food Safety Authority has encouraged international data-pooling to better assess risks in children, adolescents, and young adults.

\section{Educational and regulatory recommendations}

Diet and substance-use histories should include screening for episodic/chronic EDs consumption, both alone and with alcohol.

${ }^{\star}$ Correspondence to: Maurizio Santomauro, MD, FESC, FHRS, Department of Cardiology, Cardiac Surgery end Cardiovascular Emergency, Medical School, Federico II University, Via Sergio Pansini 5- 80131 Naples, Italy, E-mail: santomau@unina.it

Received: October 17, 2018; Accepted: October 29, 2018; Published: October 31,2018 
Screening is especially important for athletes, children with highrisk behaviors, certain health conditions (eg, seizures, diabetes, hypertension, cardiac abnormalities) and in pregnant women. For most children, adolescents, and young adults, safe levels of consumption have not been established. Yet, heavy use may be harmful or interact with medications and cause untoward adverse effects. Health care providers should educate families and children at risk for the potential adverse effects of EDs. Routine high school athletic physicals do not identify everyone at risk for sudden cardiac death. Children and their parents with cardiac conditions should be counseled regarding the risks of caffeine-containing products, including irregular heart rhythms, syncope and sudden death. Community partners, including schools, athletic groups, and regulatory bodies, also need to promote risk awareness. This approach is essential for reducing morbidity and mortality, encouraging research, and supporting families of children and young adults at risk for EDs overdose, behavioral changes, and acute/chronic health consequences. The American Association of Poison Control Centers are the governmental agency responsible for collecting the information on all the ways people are poisoned each year [21]. They publish a very detailed annual report documenting reported cases during that given year. Looking at the above data, we can draw a few conclusions : Do not consume more than 1 can $(250$ $\mathrm{mL}$ ) of an EDs per day; Avoid EDs consumption before or during sports practice; Individuals with diagnosed cardiovascular anomalies should consult cardiologists before drinking EDs; Do not combine ED consumption and alcohol or other drugs; Parents and Schools should provide continual advice against overconsumption/abuse of EDs.

Because caffeine is being put into products that are especially appealing to teens, teens can pretty quickly consume too much caffeine without realizing it. No one would argue that other substances are far more dangerous, but other drugs aren't specifically marketed to the younger demographic as EDs are. Pediatricians need to be aware of the possible effects of EDs in vulnerable populations and screen for consumption to educate families. Long-term research should aim to understand the effects in at-risk populations. Toxicity surveillance should be improved, and regulations of energy drink sales and consumption should be based on appropriate research. In 2013 the Canadian Journal of Cardiology [22] published a comprehensive study that looked at the incidences of cardiac events after EDs consumption among teens. They found that EDs abuse among teens did cause increased risk of cardiac events especially in those with underlying heart conditions and there were even some cases of EDs causing changes in heart rhythm among teens with healthy hearts. This risk increases when the child engages in sports or exercise. The researchers therefore have the following recommendations for safe use of EDs among this age group. In the 2014 the National Federation of State High School Associations (NFHS) Sports Medicine Advisory Committee (SMAC) published the Position Statement and Recommendations for the use of EDs by young athletes [23]. It strongly recommends that: EDs should not be consumed by athletes who are dehydrated; EDs should not be consumed without prior medical approval, by athletes taking over the counter or prescription medications. There are some clear instances where ED consumption by adults should be avoided; one notable example is a patient with underlying QTc prolongation or one using potentiating medications [14]. At the very least, providers should obtain a baseline electrocardiogram and inquire about ED consumption to evaluate the risk of QTc prolongation in patients before prescribing medications implicated in cardiac abnormalities. Health Canada used scientific data on the health hazard posed by caffeine to establish recommended maximum daily intake values for children $(2.5 \mathrm{mg} / \mathrm{kg}$ bw/day), adults $(6.0 \mathrm{mg} / \mathrm{kg}$ bw/day) and women of reproductive age $(4.6 \mathrm{mg} / \mathrm{kg}$ bw/day) $[24,25]$. As a precautionary approach, adolescents can be considered to be as sensitive as children to caffeine. To date, for healthy adults FDA has cited $400 \mathrm{mg}$ a day as a safe consumption limit; however, they have not set a level of safe consumption of caffeine for younger people. In 2013, the International Sport Society stated that EDs contain many ingredients which need further studies to demonstrate their safety and potential harmful effects. They therefore recommended that children and adolescents should not consume EDs without parental permission [26]. In 2013, Health Canada stipulated that the daily caffeine intake for younger children should not be greater than $2.5 \mathrm{mg} / \mathrm{kg}$ of body weight [22]. Thus, EDs are not recommended. In 2016 the European Parliament rejected the proposal of European Union Commision of promoting the Energy Drinks as a " human performances enhancer" because of potentially dangerous consequences of their inappropriate use. The label should state the following warning: "This product is not permitted for pregnant women, or women breast feeding, children under 16 years of age, persons susceptible to allergy by caffeine, or persons suffering from heart disease or athletes during sport practice". The Table 1 resumes the suggestions for EDs consumption respect to age and medical conditions. Table 2 resume the diseases at risk population do no consume EDs.

Table 1. Suggestions for energy drink consumption. Age and medical condition recommandations

\begin{tabular}{|c|c|}
\hline Age & Recommendations \\
\hline$<16$ years old & DO NOT consume EDs \\
\hline $\begin{array}{c}\text { D16 years old (healty, not pregnant and no } \\
\text { medications) }\end{array}$ & $\begin{array}{c}\text { No more than 1 regular can of EDs/day } \\
\text { at rest } \\
\text { DO NOT consume EDs prior to exercise } \\
\text { DO NOT consume EDs with alcohol }\end{array}$ \\
\hline$\geq 16$ years old & DO NOT consume EDs \\
\hline
\end{tabular}

Table 2. Do not consume EDs: warning for at-risk young adolescent populations

\begin{tabular}{|c|c|}
\hline 1 & Idiopathic Dilated Cardiomyopathy \\
\hline 2 & Hypertrophic Cardiomyopathy \\
\hline 3 & Ventricular Arrhythmogenic Cardiomyopathy \\
\hline 4 & Restrictive Cardiomyopathy \\
\hline 5 & Surgically corrected Congenital Heart defects \\
\hline 6 & Congenital Coronaric Abonormalities \\
\hline 7 & Hyperthyroidism \\
\hline 8 & Brugada Syndrome \\
\hline 9 & Iatrogenic or Congenital Long QT syndrome \\
\hline 10 & Iatrogenic or Congenital Short QT syndrome \\
\hline 11 & Wolf Parkinson White syndrome \\
\hline 12 & Atrioventricular Reciprocating Tachycardia \\
\hline 13 & Catecholaminergic Polymorphic Ventricular Tachycardia \\
\hline 14 & Bundle Branch Reentrant Ventricular Tachycardia \\
\hline 16 & Arterial Hypertension \\
\hline 17 & Increased heart rate \\
\hline 18 & Coronary artery spasm \\
\hline 19 & Coronary artery thrombosis \\
\hline 20 & Tako-tsubo Cardiomyopathy \\
\hline 21 & History of Sudden Cardiac Death \\
\hline 22 & Endothelial dysfunction \\
\hline & \\
\hline
\end{tabular}




\section{Conflicts of interest}

The authors have no conflict of interest to declare.

\section{References}

1. Mangi MA, Rehman H, Rafique M, Illovsky M (2017) Energy drinks and the risk of cardiovascular disease: a review of current literature. Cureus 9: e1322. [Crossref]

2. Enriquez A, Frankel DS (2017) Arrhythmogenic effects of energy drinks. $J$ Cardiovasc Electrophysiol 28: 711-717. [Crossref]

3. De Sanctis V, Soliman N, Soliman AT, Elsedfy H, Di Maio S, et al. (2017) Caffeinated energy drink consumption among adolescents and potential health consequences associated with their use: a significant public health hazard. Acta Biomed 88: 222-231. [Crossref]

4. Nowak D, Jasionowski A (2015) Analysis of the consumption of caffeinated energy drinks among polish adolescents. Int J Environ Res Public Health 12: 7910-7921. [Crossref]

5. Visram S, Cheetham M, Riby DM, Crossley SJ, Lake AA (2016) Consumption of energy drinks by children and young people: A rapid review examining evidence of physical effects and consumer attitudes. BMJ Open 6: e 010380.

6. Richards G, Smith AP (2016) Caffeine consumption and general health in secondary school children: a cross-sectional and longitudinal analysis. Front Nutr 28: 3:52.

7. Seifert SM, Schaechter JL, Hershorin ER, Lipshultz SE (2011) Health effects of energy drinks on children, adolescents, and young adults. Pediatrics 127: 511-528. [Crossref]

8. Zucconi S, Volpato C, Adinolfi F, Gandini E, Gentile E, et al. (2013) Gathering consumption data on specific consumer groups of energy drinks. Supporting Publication 10: 1-194.

9. Santomauro M, Palma G, Castellano G, Iannelli G, Riganti C, et al. (2017) Overconsumption of energy drink in young student of naples abstract issue of the 13th annual congress of the european cardiac arrhythmia society. J Int Cardiol Electrophysiology 48: S128.

10. Di Rocco JR, During A, Morelli PJ, Heyden M, Biancaniello TA (2011) Atrial fibrillation in healthy adolescents after highly caffeinated beverage consumption: two case reports. J Med Case Rep 5: 18. [Crossref]

11. Sanchis-Gomar F, Pareja-Galeano H, Cervellin G, Lippi G, Earnest CP (2015) Energy drink overconsumption in adolescents: implications for arrhythmias and other cardiovascular events. Can J Cardiol 31: 572-575. [Crossref]

12. Sattari M, Sattari A, Kazory A (2016) Energy drink consumption and cardiac complications: a case for caution. J Addict Med 10: 280-282. [Crossref]
13. Rottlaender D, Motloch LJ, Reda S (2012) Cardiac arrest due to long QT syndrome associated with excessive consumption of energy drinks. Int J Cardiol 158: 0-52. [Crossref]

14. Cheng M, Hu Z, Lu X (2014) Caffeine intake and atrial fibrillation incidence: dose response meta-analysis of prospective cohort studies. Can J Cardiol 30: 448-454. [Crossref]

15. Nagajothi N, Khraisat A, Velazquez-Cecena JL (2008) Energy drink-related supraventricular tachycardia. Am J Med. 121: 0-4. [Crossref]

16. Goldfarb M, Tellier C, Thanassoulis G (2014) Review of published cases of adverse cardiovascular events after ingestion of energy drinks. Am J Cardiol 113: 168-172.

17. Dufendach KA, Horner JM, Cannon BC (2012) Congenital type 1 long QT syndrome unmasked by a highly caffeinated energy drink. Heart Rhythm 9: 285-288.

18. Rutledge M, Witthed A, Khouzam RN (2012) It took a RedBull to unmask brugada syndrome. Int J Cardiol 161: e14-15. [Crossref]

19. Ward AE, Lipshultz SE, Fisher SD (2014) Energy drink-induced near-fatal ventricular arrhythmia prevented by an intracardiac defibrillator decades after operative "repair" of tetralogy of Fallot. Am J Cardiol 114: 1124-1125.

20. Glatter K A, Myers R, Chiamvimonvat N (2012) Recommendations regarding dietary intake and caffeine and alcohol consumption in patients with cardiac arrhythmias: what do you tell your patients to do or not to do? Curr Treat Options Cardiovasc Med 14: 529-535.

21. Mowry J B , Spyker D A, Louis R, Cantilena JR, MCMillan N, et al. (2013) Annua report of the american association of poison control centers ' national poison data system (NPDS): 31st Annual Report. Clinical Toxicology 52: 1032-1283.

22. Rotstein J, Barber J, Stowbridge C, Hayward H, Huang R, et al. (2013) Energy drinks an assessment of the potential health risks in the Canadian context. International Food Risk Analysis Journal 3: 1-29.

23. Position Statement and recommendations for the use of energy drinks by young athletes. National federation of State High School Association (NFHS) and Sport Medicine Advisory Committee (SMAC) 2014 Available online: www.smac/publications

24. Larson N, Laska MN, Story M, Neumark-Sztainer D (2015) Sports and energy drink consumption are linked to health-risk behaviours among young adults. Public Health Nutr 18: 2794-2803. [Crossref]

25. Gray B, Ingles J, Medi C, Driscoll T, Semsarian C (2017) Cardiovascular effects of energy drinks in familial long qt syndrome: a randomized cross-over study. Int $J$ Cardiol 231: 150-154. [Crossref]

26. John P, Higgins, Santi Yarlagadda Benjamin Yang (2015) Cardiovascular complications of energy drinks. Beverages 1: 104-126.

Copyright: (C2018 Santomauro M. This is an open-access article distributed under the terms of the Creative Commons Attribution License, which permits unrestricted use, distribution, and reproduction in any medium, provided the original author and source are credited. 